\title{
Everolimus-eluting stents in interventional cardiology
}

This article was published in the following Dove Press journal:

Vascular Health and Risk Management

26 June 2012

Number of times this article has been viewed

\author{
Jacob C Townsend \\ Phillip Rideout \\ Daniel H Steinberg \\ Division of Cardiology, Medical \\ University of South Carolina, \\ Charleston, SC, USA
}

Correspondence: Daniel H Steinberg MUSC Division of Cardiology,

25 Courtenay Drive, ART 7058,

Charleston, SC 29425, USA

Tel + I 8438764787

Email steinbe@musc.edu

\begin{abstract}
Bare metal stents have a proven safety record, but limited long-term efficacy due to in-stent restenosis. First-generation drug-eluting stents successfully countered the restenosis rate, but were hampered by concerns about their long-term safety. Second generation drug-eluting stents have combined the low restenosis rate of the first generation with improved long-term safety. We review the evolution of drug-eluting stents with a focus on the safety, efficacy, and unique characteristics of everolimus-eluting stents.
\end{abstract}

Keywords: everolimus-eluting stents, safety, efficacy

\section{Introduction}

Since the advent of percutaneous intervention, the goal of interventional cardiology has been maximizing the safety and efficacy of coronary revascularization. Angioplasty was a successful antianginal therapy in the short term, but acute adverse events and a high rate of restenosis reduced its long-term effectiveness. ${ }^{1}$ While the introduction of bare metal stents improved upon the safety of angioplasty, long-term results were limited by neointimal hyperplasia leading to in-stent restenosis. ${ }^{2}$ Drug-eluting stents dramatically reduced the in-stent restenosis seen with bare metal stents, but their long-term inhibition of neointimal growth slightly increased the risk of late-stent thrombosis. ${ }^{3}$ Second-generation stents, with multiple improvements over the earlier drug-eluting stents, appear to preserve the antirestenotic benefits, while mitigating the long-term risk of stent thrombosis. ${ }^{4,5}$ We review the background of stent evolution to highlight the efficacy, safety, and unique qualities of everolimus-eluting stents, one of the most effective and safe second-generation drug-eluting stents.

\section{Angioplasty}

Percutaneous transluminal coronary angioplasty (PTCA) was pioneered as a solution for chronic angina. While modern medical therapy is appropriate as an initial strategy in stable patients with mild angina, roughly one third of patients develop progressive or refractory angina and require invasive treatment over time. ${ }^{6}$ The RITA-2 (second Randomised Intervention Treatment of Angina) study compared PTCA with medical therapy and demonstrated reduced angina and dyspnea, improved exercise capacity, and a reduced need for antianginal medications with PTCA. ${ }^{1}$

The success of PTCA was limited by concerns over safety and efficacy. In RITA-2, $5 \%$ of patients in the PTCA arm had acute vessel closure or a flow-limiting dissection. ${ }^{1}$ Even in successful procedures, restenosis was common. More than one-fifth of patients 
required additional invasive procedures over the following 3 years. In the era of PTCA, restenosis was attributable to three factors: early elastic recoil, arterial remodeling, and neointimal hyperplasia. ${ }^{7}$ It was to address these limitations that bare metal stents were developed.

\section{Bare metal stents}

Providing a structurally stable scaffold with high radial strength, stents reduced PTCA failure by preserving lumen integrity after balloon inflation and resisting post angioplasty vessel recoil. Indeed, stent implantation not only reduced the rate of acute vessel closure, but also reduced restenosis by approximately $30 \%$ compared with PTCA. ${ }^{2,8,9}$ Despite these improvements restenosis continued to occur at a rate of $20 \%-30 \% .^{2,8,10}$ This restenosis, resulting from vessel injury and a predictable, insidious proliferation of smooth muscle cells, typically occurs within 5-6 months after stent placement. ${ }^{11}$

\section{Drug-eluting stents}

Drug-eluting stents were developed in an effort to counter this proliferative process and reduce the rates of restenosis (Table 1). These stents, beginning with sirolimus-eluting stents in 2003 and paclitaxel-eluting stents in 2004, were designed to distribute antiproliferative drugs at the site of injury during the early phase of vessel healing. ${ }^{12-14}$

There are three components to a drug-eluting stent. The first is the stent platform. Early drug-eluting stents were made of stainless steel, with a transition to thinner strut compositions such as cobalt chromium and platinum chromium. The second component is a polymer that controls the release of the eluting medication and the timing of drug delivery. Generally, polymers are a permanent part of the stent, with improvements over time, including the development of biocompatible and even bioabsorbable polymers. The final component is the eluting drug. Through the development of drug-eluting stents, each of these components has been

Table I Development of bare metal and drug-eluting stents led to a reduction in rates of abrupt closure, emergent CABG, restenosis and target lesion revascularization when compared with PTCA $2,13,14$

\begin{tabular}{llll}
\hline & PTCA & BMS & DES \\
\hline Abrupt closure & $4 \%$ & I\% & $0 \%-0.2 \%$ \\
Death/emergency & Death (0.4\%) & Death (0.4\%) & Death $(0.2 \%)$ \\
CABG & CABG (I.6\%) & CABG (I.9\%) & CABG (0\%) \\
Restenosis & $32 \%$ & $22 \%$ & $3.2 \%-3.4 \%$ \\
Target lesion & $23.3 \%$ & $13.5 \%$ & $2.4 \%-3.6 \%$ \\
revascularization & & & \\
\hline
\end{tabular}

Abbreviations: BMS, bare metal stents; CABG, coronary artery bypass surgery; DES, drug-eluting stents; PTCA, percutaneous transluminal coronary angioplasty. changed in a continued search for the best means of preventing restenosis while preventing stent thrombosis.

\section{First generation drug-eluting stents Sirolimus}

The drug rapamycin (sirolimus) was first discovered on Easter Island as a potential antifungal agent. ${ }^{15}$ Greater potential was later found for its anti-inflammatory and antiproliferative properties that have since made sirolimus a part of cancer therapy and transplant rejection treatment. ${ }^{16,17}$ It was these properties, which inhibit proliferation of leukocytes and smooth muscle cells, that rendered the drug attractive in preventing neointimal hyperplasia and clinical restenosis. ${ }^{18,19}$

The Cypher stent $\left(\right.$ Cordis $^{\circledR}$, Miami Lakes, FL) was the first drug-eluting stent approved in the United States. The stent was constructed of a 316 L stainless steel Bx Velocity ${ }^{\text {TM }}$ platform with $140 \mu \mathrm{m}$ struts. The platform was then covered with a biocompatible poly n-butyl methacrylate polymer and finally sirolimus, ${ }^{20}$ a combination that resulted in drug release over 30 days.

Although a number of smaller studies demonstrated the potential efficacy of sirolimus-eluting stents, RAVEL (Randomized Study with the Sirolimus-Coated Bx Velocity Balloon-Expandable Stent in the Treatment of Patients with de Novo Native Coronary Artery Lesions) was the first large study to compare sirolimus-eluting stents with bare metal stents, randomizing 238 patients undergoing percutaneous coronary intervention. ${ }^{12}$ At 1 year, patients treated with a sirolimus-eluting stent had significantly less late lumen loss $(-0.01 \mathrm{~mm}$ versus $0.8 \mathrm{~mm} ; P<0.001)$, less angiographic restenosis (none in sirolimus-eluting stents versus $26.6 \%$ in bare metal stents; $P<0.001$ ), and fewer major cardiac events. Importantly, this difference was driven entirely by restenosis. These encouraging early results persisted, and at 5 years the need for target vessel revascularization was significantly lower in patients with a sirolimus-eluting stent (11\% versus $23 \% ; P \leq 0.001) .{ }^{21}$

This was followed by the SIRIUS (sirolimus-eluting stents versus standard stents in patients with stenosis in a native coronary artery) study, in which patients with both stable and unstable coronary artery disease were randomized to receive a sirolimus-eluting stent or bare metal stent. ${ }^{13}$ At 9 months, significant reductions were seen in angiographic in-stent restenosis ( $3 \%$ versus $35 \%$; $P \leq 0.001)$, late lumen loss $(0.17 \mathrm{~mm}$ versus $1 \mathrm{~mm} ; P \leq 0.001)$, and target lesion revascularization ( $4 \%$ versus $17 \% ; P \leq 0.001)$. As in RAVEL, the initial reduction in in-stent restenosis was sustained out to 5 years of follow-up, with target lesion revascularization being 
significantly less frequent in patients receiving a sirolimuseluting stent $(9.4 \%$ versus $24.2 \% ; P \leq 0.001)$. Importantly, in a finding to be seen in other comparisons of bare metal stents and drug-eluting stents, no differences in myocardial infarction, death, or stent thrombosis were noted between the sirolimus-eluting stent and the bare metal stent. ${ }^{22}$

Even outside of selected study patient populations, realworld registries have shown similar results. The RESEARCH (Rapamycin-Eluting Stent Evaluated At Rotterdam Cardiology Hospital) registry compared sirolimus-eluting stent outcomes with those in 450 historical controls treated with bare metal stents. Despite a higher incidence of multivessel disease, complex lesions, increased stent use, and bifurcation stenting, the sirolimus-eluting stent group had significantly fewer major adverse cardiac events $(9.7 \%$ versus $14.8 \% ; P=0.008$ ) and less ischemia-driven target vessel revascularization $(3.7 \%$ versus $10.9 \%$; $P<0.001)$ at one year of follow-up. ${ }^{23}$

The results seen in stable patients were later confirmed in those with ST elevation myocardial infarction. TYPHOON (the Trial to Assess the Use of the Cypher Stent in Acute Myocardial Infarction Treated with Balloon Angioplasty) randomized 712 patients with acute myocardial infarction to receive either a sirolimus-eluting stent or a bare metal stent and demonstrated that one-year rates of target lesion revascularization were significantly reduced in patients treated with a sirolimus-eluting stent $(5.6 \%$ versus $13.4 \% ; P<0.001)$. Additionally, there was significantly less late lumen loss in the sirolimus-eluting stent group $(0.14 \mathrm{~mm}$ versus $0.83 \mathrm{~mm}$; $P<0.001)$ at 8 months compared with bare metal stents. ${ }^{24}$

\section{Paclitaxel}

Paclitaxel was originally isolated from the bark of the Pacific yew tree. Its inhibition of microtubule breakdown during cell synthesis inhibits cellular replication and has made it an ideal platform for the treatment of malignancy. Like sirolimus, this antiproliferative property has also translated into a reduction in smooth muscle proliferation and consequently a reduction in in-stent restenosis. ${ }^{25}$

The Taxus stent (Boston Scientific, Natick, MA) was the first stent marketed with paclitaxel as the eluting agent. The stent was constructed on a $316 \mathrm{~L}$ stainless steel Express 2 stent platform with $132 \mu \mathrm{m}$ struts. A proprietary Transulte ${ }^{\circledR}$ [poly(styrene-b-isobutylene-b-styrene)] polymer bound paclitaxel to the platform and resulted in drug release over 90 days.

The Taxus series of studies examined the effect of paclitaxel-eluting stents compared with bare metal stents.
Taxus I was a small first-in-man study in which patients were randomized to receive either a paclitaxel-eluting stent or a bare metal stent in a randomized, double-blind fashion. Follow-up at 12 months showed significant reductions in late lumen loss and minimal luminal diameter, as well as significantly less neointimal hyperplasia in patients treated with a paclitaxel-eluting stent. ${ }^{26}$ Taxus II, which included 536 patients, examined the effects of slow-release and moderate-release formulations of paclitaxel compared with bare metal stents, and found similar significant reductions in neointimal formation and restenosis at 6 months, as well as reduced target lesion revascularization at 12 months. ${ }^{27}$ Taxus IV definitively demonstrated the superiority of the paclitaxel-eluting stent in 1514 patients undergoing percutaneous coronary intervention randomized to receive a bare metal stent or a paclitaxel-eluting stent. In this large population, paclitaxel-eluting stent implantation led to significant reductions in angiographic restenosis ( $8 \%$ versus $27 \%$; $P \leq 0.001)$ and target lesion revascularization $(3 \%$ versus $11 \% ; P \leq 0.001)$, without a difference in stent thrombosis or myocardial infarction at 9 months. ${ }^{14}$

Finally, just as was seen with sirolimus-eluting stents, paclitaxel-eluting stents have been shown to reduce the need for target vessel revascularization when compared with bare metal stents in the setting of acute myocardial infarction. In the HORIZONS-AMI (Harmonizing Outcomes with Revascularization and Stents in Acute Myocardial Infarction) trial, 3006 patients were randomized in a $3: 1$ fashion to receive either a bare metal stent or a paclitaxel-eluting stent. In this study, the paclitaxel-eluting stents had significantly lower 12-month rates of target vessel revascularization $(5.8 \%$ versus $8.7 \% ; P=0.006)$, without an increased risk of death or stent thrombosis. ${ }^{28}$

\section{Sirolimus-eluting versus paclitaxel-eluting stents}

With conclusive evidence that paclitaxel-eluting and sirolimus-eluting stents reduce restenosis and the need for repeat target lesion revascularization when compared with bare metal stents, the REALITY study looked for differences between these two drug-eluting stents. The investigators randomized 1386 patients with angina to receive a sirolimuseluting stent or a paclitaxel-eluting stent. At 8 months of angiographic follow-up and 12 months of clinical follow-up, no significant differences in binary restenosis or major adverse cardiac events were detectable. ${ }^{29}$

In the SIRTAX (Sirolimus-Eluting Stent Compared with Paclitaxel-Eluting Stent for Coronary Revascularization) trial, 
1012 patients were randomized to receive a sirolimus-eluting stent or a paclitaxel-eluting stent. Target lesion revascularization was significantly reduced with the sirolimus-eluting stent $(4.8 \%$ versus $8.3 \% ; P=0.009)$, as was angiographic restenosis $(6.6 \%$ versus $11.7 \% ; P=0.02$ ) at 12 months, without differences in rates of cardiac death or myocardial infarction. ${ }^{30}$ However, by 5 years of follow-up, the advantage of the sirolimus-eluting stent over the paclitaxel-eluting stent was no longer evident, with no significant differences in angiographic restenosis, myocardial infarction, or target lesion revascularization. ${ }^{31}$

The SORT-OUT II (comparison of paclitaxel-eluting and sirolimus-eluting stents in everyday clinical practice) trial also compared sirolimus-eluting and paclitaxel-eluting stents using real-world inclusion criteria that encompassed acute coronary syndromes and even ST elevation myocardial infarction. The investigators randomized 2098 patients and found no significant differences between the two groups with regard to target lesion revascularization, cardiac death, or myocardial infarction at 9 months. ${ }^{32}$ These findings are supported by other large, real-world, multicenter registries. ${ }^{33-35}$

\section{Safety}

Drug-eluting stents were developed to reduce the risk of restenosis, and in that regard were highly successful. Early trials were designed to assess efficacy and safety during the clinical window in which restenosis occurs, and therefore follow-up was generally 12 months or less. As the above studies attest, few safety concerns were noted and the rates of stent thrombosis and myocardial infarction were generally equivalent at one year. As long-term follow up accrued, a trend toward increased very late stent thrombosis (more than one year following drug-eluting stent implantation) was noted. ${ }^{36-38}$ Pooled analysis of patient level data from four large randomized trials comparing sirolimus-eluting and paclitaxel-eluting stents with bare metal stents found that although the incidence of stent thrombosis was not significantly different between the groups, the absolute rates of stent thrombosis were nearly twice as high in patients treated with a drug-eluting stent $(1.2 \%$ sirolimus-eluting stents versus $0.6 \%$ bare metal stents; $P=0.2 ; 1.3 \%$ paclitaxel-eluting stents versus $0.8 \%$ bare metal stents; $P=0.24){ }^{3}$

Stent thrombosis can result from multiple factors (Figure 1) pertaining to the patient, the lesion, the clinical scenario, or the stent itself. Importantly, some of these factors are modifiable, such as those relating to patient compliance and stent properties, while others are not. Regarding stentspecific factors, both autopsy and in vivo studies have identified an association between stent thrombosis and incomplete stent endothelialization. ${ }^{39,40}$ As Joner et al demonstrated in their study of late (more than 30 days post intervention) stent thrombosis, patients with drug-eluting stent thrombosis had increased inflammation and delayed endothelial healing, while bare metal stent thrombosis was due entirely to in-stent restenosis. Delayed healing and incomplete endothelialization have been identified in drug-eluting stents as late as 40 months post implantation. ${ }^{40}$

Stent endothelialization is affected by both the platform and polymer, both of which may play a role in stent thrombosis. Virmani et al were the first to report thrombosis associated with a hypersensitivity reaction to the sirolimus-eluting stent
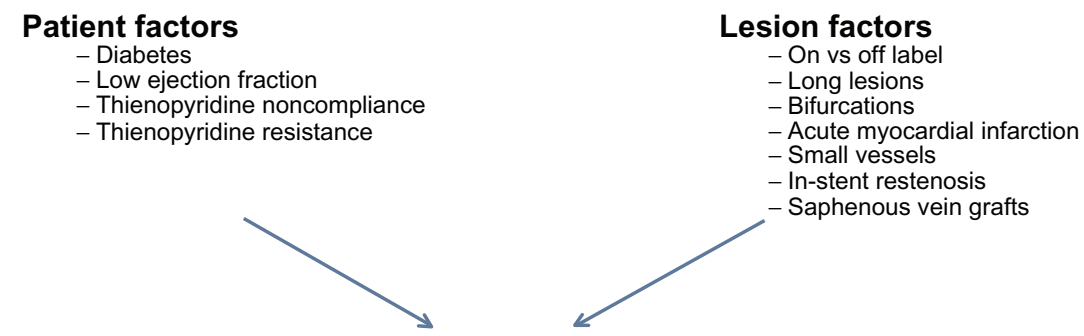

\section{Thrombosis}
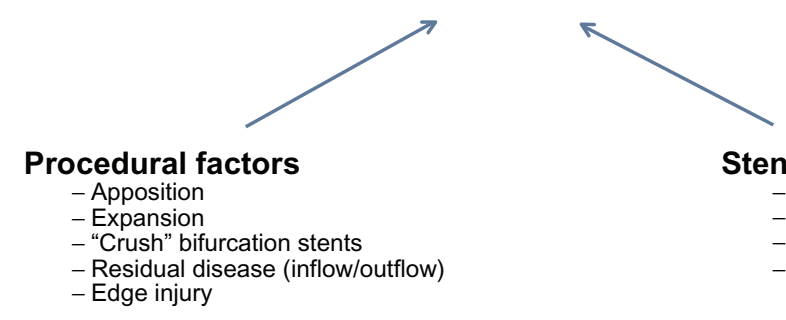

Stent factors

- Hypersensitivity

- Drug/polymer

- Delayed healing

- Incomplete endothelialization

Figure I Summary of major factors associated with stent thrombosis. 
polymer. ${ }^{41}$ Further studies have suggested that various stent strut sizes and alloys have divergent rates of underlying endothelial cell recovery, with the highest rates of endothelialization seen with the thinnest struts. ${ }^{42}$ Finally, differences in platelet adhesion and thrombus formation have been demonstrated between stent platforms. ${ }^{43}$ This knowledge led to targeted improvements in the next generation of drug-eluting stents.

\section{Second generation drug-eluting stents}

The first generation of drug-eluting stents had an identical stent structure to their bare metal stents counterparts, with polymer and eluting drug applied to the surface. The platform was stainless steel with a strut thickness of 130-140 $\mu \mathrm{m}$. Second-generation drug-eluting stents, in addition to incorporating newer medications (everolimus and zotarolimus) and more biocompatible polymers, utilize a cobalt or platinum chromium platform, with stent struts measuring only $80-90 \mu \mathrm{m}^{44}$ (Table 2). This reduction in stent strut size improves stent flexibility and deliverability, but more importantly has been shown to improve endothelialization in animal models. ${ }^{42}$

\section{Zotarolimus}

Zotarolimus is a lipophilic derivative of sirolimus. The Endeavor $^{\circledR}$ stent (Medtronic, Minneapolis, MN) consists of a thin-strut, cobalt-chromium platform with a biocompatible phosphorylcholine polymer that elutes zotarolimus over a two-week period. A second iteration of the zotarolimuseluting stent (Resolute ${ }^{\circledR}$; Medtronic) with a prolonged elution time, is discussed later in comparison with the everolimuseluting stent.

The ENDEAVOR (Endeavor zotarolimus-eluting phosphorylcholine-encapsulated stent for treatment of native coronary artery lesions) trials evaluated the first iteration of the zotarolimus-eluting stent. This stent was compared with the bare metal stent in the ENDEAVOR II trial. As expected, target lesion revascularization was significantly reduced (4.6\% versus $11.8 \% ; P=0.0001)$ at 9 months, a finding that persisted at 12 and 24 months of follow-up. In addition to demonstrating efficacy, the zotarolimus-eluting stent was also shown to be very safe, with a low (0.5\%) risk of stent thrombosis, similar to what was seen in the bare metal stent arm. ${ }^{45}$

The ENDEAVOR IV trial compared the zotarolimuseluting and paclitaxel-eluting stents in patients with stable coronary disease. ${ }^{46}$ At 12 months, there were no significant differences in target lesion revascularization or binary angiographic restenosis. By 3 years, the rate of ischemiadriven target lesion revascularization continued to be similar for the zotarolimus-eluting and paclitaxel-eluting stents (6.5\% versus $6.1 \% ; P=0.66)$, but the risk of very late stent thrombosis (years 1-3), a concern with first-generation drug-eluting stents, occurred much less frequently with the zotarolimus-eluting stent $(0.1 \%$ versus $1.6 \% ; P=0.004){ }^{4}$ These findings suggest that, at least compared with the paclitaxel-eluting stent, the zotarolimus-eluting stent was as effective at preventing in-stent restenosis while offering an improved long-term safety profile.

Two trials have compared the zotarolimus-eluting and sirolimus-eluting stents. ENDEAVOR III randomized 436 patients 3:1 to either a zotarolimus-eluting stent or a sirolimus-eluting stent. At 9 months, the zotarolimus-eluting stent showed significantly more late lumen loss $(0.34 \mathrm{~mm}$ versus $0.13 \mathrm{~mm} ; P<0.001)$ and binary restenosis $(11.7 \%$ versus $4.3 \% ; P=0.04) .{ }^{47}$ Clinically-driven target lesion revascularization occurred more frequently with the zotarolimus-eluting stent ( $6.3 \%$ versus $3.5 \% ; P=0.34)$, although the finding was not statistically significant. The SORT OUT III trial randomized 2332 patients with slightly higher clinical acuity to receive either the zotarolimus-eluting stent or the sirolimus-eluting stent. ${ }^{48}$ Clinically-driven target lesion revascularization was again lower with the sirolimus-eluting stent (1\% versus $3 \%$; $P<0.001)$ at 9 months, with an advantage that continued at 18 months ( $1 \%$ versus $5 \% ; P<0.001)$. The need for repeat intervention was greater in those treated with the zotarolimuseluting stent, but no cases of late stent thrombosis occurred in this group between 9 and 18 months.

The ZEST (comparison of the efficacy and safety of zotarolimus-eluting stent with sirolimus-eluting and

Table 2 Comparison of the platform composition, strut thickness, and polymer of major drug-eluting stents

\begin{tabular}{|c|c|c|c|c|c|c|}
\hline & SES (Cyper) & PES (TAXUS) & ZES (Endeavor) & ZES (Resolute) & EES (Xience) & EES (Promus element) \\
\hline \multirow[t]{2}{*}{ Composition } & L3I 6 & L3I6 & Co-cr & $\mathrm{Co}-\mathrm{Cr}$ & $\mathrm{Co}-\mathrm{Cr}$ & $\mathrm{PI}-\mathrm{Cr}$ \\
\hline & Bx Velocity & Express & Driver & Integrity & Vision & Element \\
\hline Strut thickness & $140 \mu \mathrm{m}$ & $132 \mu \mathrm{m}$ & $91 \mu \mathrm{m}$ & $91 \mu \mathrm{m}$ & $81 \mu \mathrm{m}$ & $81 \mu \mathrm{m}$ \\
\hline Polymer & PEVA/PBMA & Translute SIBS & Phosphorycholine & BioLinx & PBMA & PBMA \\
\hline
\end{tabular}

Abbreviations: PEVA, polyethylene-co-vinyl acetate; PBMA, poly-n-butyl methacrylate; SIBS, poly(styrene-b-isobutylese-b-styrene); SES, sirolimus-eluting stent; PES, paclitaxel-eluting stent; EES, everolimus-eluting stent; ZES, zotarolimus-eluting stent. 
paclitaxel-eluting stent for coronary lesions) trial compared the zotarolimus-eluting stent with both the sirolimuseluting and paclitaxel-eluting stents. ${ }^{49}$ With a background understanding that the sirolimus-eluting stent was superior to the paclitaxel-eluting stent for prevention of restenosis, the study was designed to assess noninferiority of the zotarolimus-eluting stent compared with the sirolimuseluting stent, and to assess superiority when comparing the zotarolimus-eluting stent with the paclitaxel-eluting stent. The primary endpoint was a composite of death, myocardial infarction, and ischemic target vessel revascularization at 12 months. The zotarolimus-eluting stent was noninferior to the sirolimus-eluting stent $(10.2 \%$ versus $8.3 \% ; P=0.001)$, and superior to the paclitaxel-eluting stent $(10.2 \%$ versus $14.1 \% ; P=0.01)$. Interestingly, stent thrombosis was lowest with the sirolimus-eluting stent, which was significantly better at 12 months than with either the paclitaxel-eluting stent or the zotarolimus-eluting stent (zotarolimus-eluting versus sirolimus-eluting versus paclitaxel-eluting stent, $0.7 \%$ versus $0 \%$ versus $0.8 \% ; P=0.02$ ). While the stent thrombosis outcome may seem discrepant in comparison with earlier studies, in both ENDEAVOR IV and SORT OUT III, the benefit of the zotarolimus-eluting stent was its lack of very late stent thrombosis ( $>12$ months), which was not assessed in the ZEST trial.

\section{Everolimus}

Everolimus is a macrocyclic lactone, similar to sirolimus. ${ }^{50}$ It shares the same antiproliferative and immunosuppressive effects, but is more lipophilic, allowing rapid absorption into the arterial wall at the site of vessel injury. Although the first study to examine the efficacy of everolimus-eluting stents utilized a stainless steel platform with a biodegradable polymer, ${ }^{50}$ the dually marketed everolimus-eluting stents [Xience (Abbott Vascular, Abbott Park, IL)/Promus (Boston Scientific)] consists of a L605 cobalt-chromium stent coated with a biocompatible poly-n-butyl methacrylate polymer and everolimus.

The SPIRIT (Clinical Evaluation of the XIENCE V Everolimus Eluting Coronary Stent System in the Treatment of Subjects With de Novo Native Coronary Artery Lesions) trials (Table 3 ) formed the clinical program leading to US Food and Drug Administration approval of the everolimus-eluting stent. The SPIRIT FIRST trial compared the everolimus-eluting stent with the bare metal stent in 60 patients. At 6 months, the everolimus-eluting stent was associated with significantly less late lumen loss $(0.1 \mathrm{~mm}$ versus $0.87 \mathrm{~mm} ; P<0.001$ ) with a similar safety profile. ${ }^{51}$
Table 3 Summary of the Clinic Evaluation of the XIENCE $\vee$ Everolimus Eluting Coronary Stent System in the Treatment of Subjects with de Novo Coronary Artery Lesions (SPIRIT) trials comparing EES and PES, showing superior 12-month target lesion revascularization (target lesion revascularization) and overall restenosis results, with similar to improved rates of stent thrombosis and VLST ${ }^{52,54,55}$

\begin{tabular}{|c|c|c|c|}
\hline & SPIRIT 2 & SPIRIT 3 & SPIRIT 4 \\
\hline Comparator & EES vs PES & EES vs PES & EES vs PES \\
\hline $\mathrm{n}$ & 300 & 1002 & 3687 \\
\hline \multirow[t]{3}{*}{12 month TLR } & EES (2.7\%) & EES (8.6\%) & EES (4.2\%) \\
\hline & PES (7.9\%) & PES (II.3\%) & PES (6.8\%) \\
\hline & $P=0.04$ & $P=0.20$ & $P=0.001$ \\
\hline \multirow[t]{3}{*}{ Long-term restenosis } & EES (6.6\%) & EES (I0.7\%) & EES (6.9\%) \\
\hline & PES (II.0\%) & PES (I5.4\%) & PES (9.9\%) \\
\hline & $P=0.31$ & $P=0.04$ & $P=0.003$ \\
\hline \multirow[t]{3}{*}{ 12-month thrombosis } & EES (0.5\%) & EES $(0.8 \%)$ & $\operatorname{EES}(0.17 \%)$ \\
\hline & PES (I.3\%) & PES $(0.6 \%)$ & PES $(0.85 \%)$ \\
\hline & $P=N S$ & $P=>0.99$ & $P=0.004$ \\
\hline \multirow[t]{3}{*}{ VLST } & EES $(0.9 \%)$ & EES (I.0\%) & EES $(0.42 \%)$ \\
\hline & PES (I.4\%) & PES (I.7\%) & PES (I.23\%) \\
\hline & $P=N S$ & $P=0.35$ & $P=0.008$ \\
\hline
\end{tabular}

Abbreviations: VLST, very late stent thrombosis; EES, everolimus-eluting stents; PES, paclitaxel-eluting stents.

The SPIRIT II trial directly compared everolimus-eluting stents with paclitaxel-eluting stents. Three hundred patients were enrolled in a 3:1 randomization. At 6 months, late loss was significantly reduced with the everolimus-eluting stent (0.11 mm versus $0.36 \mathrm{~mm} ; P<0.0001) .{ }^{52}$ Interestingly, by 2 years, catch up in everolimus-eluting stent hyperplasia resulted in nearly identical late loss $(0.33 \mathrm{~mm}$ versus $0.34 \mathrm{~mm} ; P=0.84)$. Stent thrombosis between everolimuseluting stents and paclitaxel-eluting stents was not significantly different at 2 years. ${ }^{53}$

A second, larger trial again compared everolimus-eluting and paclitaxel-eluting stents. In SPIRIT III, 1002 patients were randomized 2:1 to the everolimus-eluting stent or the paclitaxel-eluting stent. At 8 months, there was significantly less late loss with the everolimus-eluting stent $(0.14 \mathrm{~mm}$ versus $0.28 \mathrm{~mm} ; P<0.04)$. At 12 months, a composite endpoint of cardiac death, myocardial infarction, and target lesion revascularization occurred less frequently with the everolimus-eluting stent ( $6 \%$ versus $10.3 \% ; P=0.02)$ due to a reduction in myocardial infarction and target lesion revascularization. ${ }^{54}$ At 2 years, the composite endpoint still favored everolimus-eluting stents $(10.7 \%$ versus $15.4 \% ; P=0.04)$. With regard to safety, the rate of stent thrombosis was low for both the everolimus-eluting stent (1\%) and the paclitaxeleluting stent (1.7\%), and not statistically different. ${ }^{5}$

The SPIRIT IV trial was designed to address the clinical differences between everolimus-eluting stents and 
paclitaxel-eluting stents. In contrast with the earlier trials, there was no angiographic follow-up, and the primary endpoint was a composite of clinical target lesion failure, composed of cardiac death, target vessel myocardial infarction, and ischemiadriven target lesion revascularization. ${ }^{55} \mathrm{~A}$ total of 3687 patients were enrolled 2:1 to receive an everolimus-eluting stent or a paclitaxel-eluting stent. At 12 months, the everolimus-eluting stent was superior for the combined endpoint (4.2\% versus $6.8 \% ; P=0.001)$. Rates of target lesion revascularization were significantly lower $(2.5 \%$ versus $4.6 \% ; P=0.001)$, as were myocardial infarction $(1.9 \%$ versus $3.1 \% ; P=0.02)$ and stent thrombosis $(0.17 \%$ versus $0.85 \% ; P=0.004)$ rates for the everolimus-eluting stent. These differences were maintained at 2 years, when target lesion failure was significantly less frequent with the everolimus-eluting stent $(6.9 \%$ versus $9.9 \% ; P=0.002) .{ }^{56}$ The differences in myocardial infarction $(2.5 \%$ versus $3.9 \% ; P=0.02)$, stent thrombosis $(0.4 \%$ versus $1.2 \% ; P=0.008)$, and ischemic-driven target lesion revascularization ( $4.5 \%$ versus $6.9 \% ; P=0.004)$ were also maintained at 2 years, showing long-term, sustained safety and efficacy when compared with the paclitaxel-eluting stent.

The COMPARE (second-generation everolimus-eluting and paclitaxel-eluting stents in real-life practice) trial continued the comparison of everolimus-eluting stents and paclitaxel-eluting stents, this time in an unselected patient population utilizing a second-generation paclitaxel-eluting stent with an improved platform. The authors included 1800 patients randomized 1:1 and assessed for a combined safety and efficacy endpoint of all-cause mortality, myocardial infarction, and target vessel revascularization at 12 months. ${ }^{57}$ The primary endpoint was seen more frequently in patients treated with paclitaxel-eluting stents $(9 \%$ versus $6 \% ; P=0.02)$. There were significant differences in the rates of stent thrombosis $(<1 \%$ versus $3 \%$; $P=0.002)$, myocardial infarction ( $3 \%$ versus $5 \% ; P=0.007)$, and target vessel revascularization $(2 \%$ versus $6 \% ; P=0.0001)$ all favoring the everolimus-eluting stent over the paclitaxeleluting stent. At two years of follow-up, the everolimus-eluting stent continued to be favorable, with fewer myocardial infarctions $(3.9 \%$ versus $7.5 \% ; P<0.001)$, less need for target vessel revascularization ( $3.2 \%$ versus $8 \% ; P<0.001)$, and less stent thrombosis $(0.9 \%$ versus $3.9 \% ; P<0.001){ }^{58}$

Despite extensive comparisons with the paclitaxeleluting stent, there are relatively few studies comparing the everolimus-eluting stent with the sirolimus-eluting stent. The X-SEARCH registry included 649 unselected patients treated with everolimus-eluting stents who were followed for 6 months for a composite endpoint of all-cause mortality, myocardial infarction, and target vessel revascularization. ${ }^{59}$
The results were then compared with a historical series of bare metal stents $(n=450)$, sirolimus-eluting stents $(n=508)$, and paclitaxel-eluting stents $(n=576)$. While the study duration and use of historical cohorts leave some questions unanswered, it is worth noting that major adverse cardiac events occurred more commonly with the bare metal stents and paclitaxel-eluting stents than with the everolimus-eluting stents. Sirolimus-eluting stents had similar outcomes to those of everolimus-eluting stents.

The EXCELLENT (Efficacy of Xience/Promus Versus Cypher to Reduce Late Loss After Stenting) trial was designed to compare angiographic differences between everolimuseluting stents and sirolimus-eluting stents. ${ }^{60}$ A total of 1443 patients were randomized 3:1 to receive the everolimus-eluting stent or the sirolimus-eluting stent. Angiographic follow-up was done at 9 months and showed the everolimus-eluting stent to be noninferior for late lumen loss $(0.11 \mathrm{~mm}$ versus $0.06 \mathrm{~mm} ; P=0.038$ for noninferiority). Clinical events at 12 months, including target lesion failure, death, nonfatal myocardial infarction, target lesion revascularization, and stent thrombosis, were not statistically different.

The second-generation drug-eluting stents were designed to improve upon the safety of the first-generation stents while maintaining their high level of antirestenotic ability. As reviewed above, the early iteration of the zotarolimuseluting stent had an excellent safety profile, but its ability to prevent restenosis was similar to that of the paclitaxel-eluting stent and less effective than the sirolimus-eluting stent. The everolimus-eluting stent, in contrast, outperformed the paclitaxel-eluting stent, with a safety and efficacy profile similar to that of the sirolimus-eluting stent. In response to the higher restenosis rates seen with the early zotarolimus-eluting stent, a second zotarolimus-eluting stent with a longer drug-eluting duration was developed (Resolute). ${ }^{61}$ A total of 2292 patients were enrolled in a trial to test this new zotarolimus-eluting stent against the everolimus-eluting stent. At 12 months, the zotarolimus-eluting stent was noninferior to the everolimuseluting stent for major cardiac events $(8.2 \%$ versus $8.3 \%$; $P<0.001$ ), without significant differences in rates of death, myocardial infarction, and target lesion revascularization. Stent thrombosis rates were also similar, occurring in $2.3 \%$ of patients who received the zotarolimus-eluting stent and $1.5 \%$ of those who received the everolimus-eluting stent $(P=0.17)$. Angiographic follow-up at 13 months in a select minority of the study population showed no significant differences in late lumen loss. From these results, it appears that the newer zotarolimus-eluting stent has improved antirestenotic ability due to a longer period of drug elution, with the need for target 
lesion revascularization occurring almost half as often at one year $(3.9 \%)$ as was seen in ENDEAVOR IV. ${ }^{46}$

\section{Everolimus use in special populations Diabetes}

Everolimus-eluting stents have been compared to first-generation drug-eluting stents in a number of percutaneous coronary intervention (PCI) settings. Of particular interest are some of the higher-risk populations undergoing PCI, including patients with diabetes, chronic total occlusions, bifurcation lesions, and instent restenosis. Important differences are summarized in Figure 2. Patients with diabetes have more than twice the risk of developing coronary artery disease. In this population, coronary disease tends to be more aggressive and has worse outcomes, regardless of the method of revascularization. ${ }^{62}$ Although drug-eluting stents have been shown to reduce event rates in patients with diabetes mellitus, differential effects of rapamycin analogs and paclitaxel have been suggested. ${ }^{63}$

The ESSENCE-DM (randomized comparison of everolimus-eluting stent versus sirolimus-eluting stent implantation for de novo coronary artery disease in patients with diabetes mellitus) trial randomized 300 patients with diabetes to receive an everolimus-eluting stent or a sirolimus-eluting stent in a 1:1 fashion. ${ }^{64}$ At 8 months, the everolimus-eluting stents had similar in-stent late loss $(0.11 \mathrm{~mm}$ versus $0.2 \mathrm{~mm}$; $P=0.114$ ). Major adverse cardiac events, including death, myocardial infarction, and ischemic target lesion revascularization, all occurred less frequently with the everolimus-eluting stent, but the differences did not reach statistical significance (2\% everolimus-eluting stent versus 5.3\% sirolimus-eluting stent, $P=0.218$ for the combined endpoint; and $0.7 \%$ everolimus-eluting stent versus $2.6 \%$ sirolimus-eluting stent, $P=0.32$ for target lesion revascularization).

While no diabetes-specific randomized trials have compared the everolimus-eluting stent and the paclitaxel-eluting stent, results from the SPIRIT II, SPIRIT III, SPIRIT IV, and COMPARE trials were combined to address this question. Among the 6780 patients originally included in those studies, $27.6 \%$ (1869) were known to have diabetes. Interestingly, despite a robust reduction in 2-year mortality, myocardial infarction, stent thrombosis, and ischemic target lesion revascularization among patients without diabetes mellitus who were treated with an everolimus-eluting stents, compared with a paclitaxel-eluting stent, no such effects were seen in patients with diabetes in either the safety or efficacy endpoints. ${ }^{65}$
A TLR in diabetics at 12 months
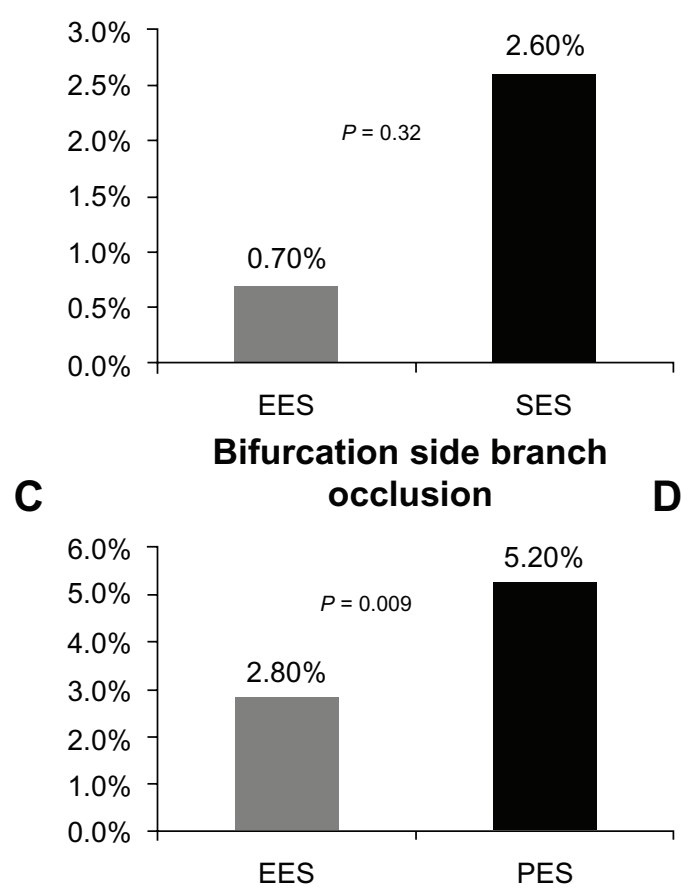

TVR in chronic total occlusions
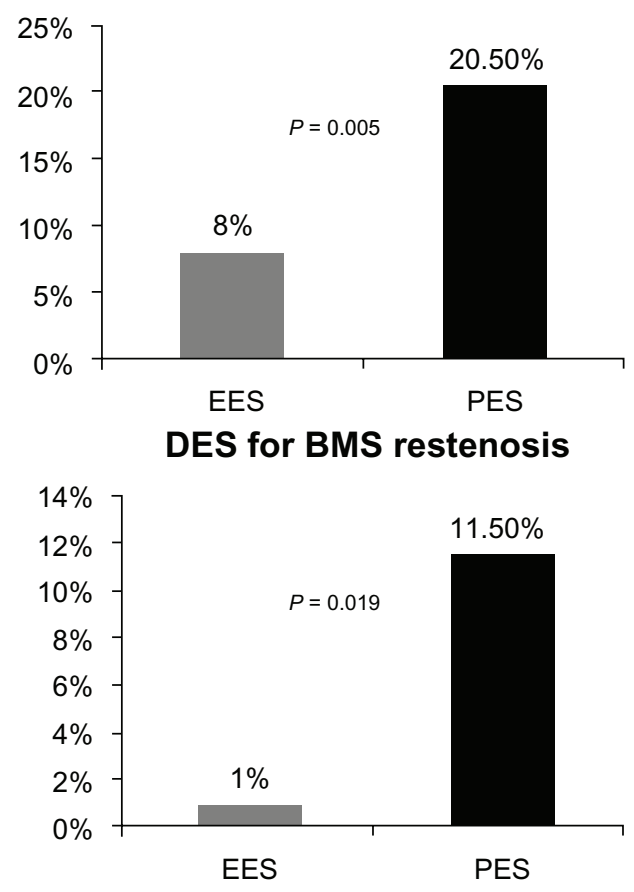

Figure 2 Everolimus use in special populations. Reduced target lesion revascularization was seen in patients with diabetes treated with the EES compared with sirolimuseluting stents (A). When compared with paclitaxel-eluting stents, the use of EES was associated with lower rates of target vessel revascularization in chronic occlusions (B), less side branch occlusion in bifurcation stenting (C), and improved restenosis rates in the treatment of BMS ISR (D).

Abbreviations: DES, drug-eluting stent; TLR, target lesion revascularization; TVR, target vessel revascularization; EES, everolimus-eluting stent; SES, sirolimus-eluting stent; PES, paclitaxel eluting stent; BMS, bare metal stent; ISR, in-stent restenosis. 


\section{Chronic total occlusions}

Chronic total occlusions are technically challenging and often require long segments of lesion coverage, with a relatively high risk of restenosis ${ }^{66}$ Consequently, drug-eluting stents, with their antiproliferative properties, are preferred. Valenti et al reported on a group of patients with long $(<40 \mathrm{~mm})$ chronic total occlusions and compared outcomes using the everolimus-eluting stent $(\mathrm{n}=112)$ and the paclitaxel-eluting stent $(\mathrm{n}=146) \cdot{ }^{67}$ At 9 months, there was significantly less binary restenosis with the everolimus-eluting stent $(11.8 \%$ versus $31.4 \% ; P=0.001$ ), with an improved overall patency rate $(98 \%$ versus $85 \% ; P=0.003)$. The need for repeat intervention was significantly lower in everolimus-eluting stent patients ( $8 \%$ versus $20.5 \% ; P=0.005$ ), and no stent thrombosis was noted among patients treated with this stent compared with five patients in the paclitaxel-eluting stent cohort.

\section{Bifurcations}

Bifurcation disease is a unique field in which individual stent characteristics play a role in outcomes. Beyond the importance of an effective eluting agent, bifurcation stenting requires a stent platform with pliable architecture. The ability to preserve side branch patency, whether by avoiding side branch occlusion, ballooning through a stent strut, or when necessary employing a second stent, is key to a successful percutaneous strategy.

Because studies of bifurcation stent strategies have shown the best outcomes associated with a provisional stenting approach compared with two stent techniques, the primary goal of treating such lesions is avoiding side branch occlusion. ${ }^{68}$ In a review of patients treated with an everolimuseluting stent $(n=669)$ or a paclitaxel-eluting stent $(n=333)$ as part of the SPIRIT III trial, transient or final side branch occlusion occurred less frequently in those with an everolimus-eluting stent than in those who had a paclitaxel-eluting stent $(2.8 \%$ versus $5.2 \% ; P=0.009) .{ }^{69}$

A prospective randomized trial by Burzotta et al reported similar findings. A total of 150 patients were randomized to receive a sirolimus-eluting stent or an everolimus-eluting stent for treatment of the main vessel in cases where the involved side branch was at least $2 \mathrm{~mm}$ in size. Everolimuseluting stents, due to a more malleable platform, resulted in a larger post intervention side branch luminal diameter (1.94 $\mathrm{mm}$ versus $1.64 \mathrm{~mm} ; P=0.13)$, with a significant difference in the rate of bifurcation failure at 18 months (everolimus-eluting stent $10.7 \%$ versus sirolimus-eluting stent $9 \% ; P=0.57) .{ }^{70}$
Another recent study retrospectively compared outcomes using the zotarolimus-eluting stent $(\mathrm{n}=110)$ and the everolimus-eluting stent $(\mathrm{n}=129)$ for bifurcation disease. ${ }^{71}$ There were no significant immediate differences in safety and efficacy between the groups, but by 12 months, those treated with the zotarolimus-eluting stent had significantly more major adverse cardiac events $(23.1 \%$ versus $4.9 \%$; $P \leq 0.001)$. This was driven primarily by target lesion revascularization, occurring in $17.6 \%$ of patients treated with the zotarolimus-eluting stent and in only $3.2 \%$ of patients treated with the everolimus-eluting stent $(P<0.001)$.

\section{Bare metal stent in-stent restenosis}

Drug-eluting stents were initially designed to prevent the instent restenosis seen with bare metal stents. The first-generation drug-eluting stents were shown not only to reduce in-stent restenosis in de novo lesions, but also to be an excellent treatment for in-stent restenosis that had developed in lesions treated initially with a bare metal stent. ${ }^{72,73}$ Likewise, everolimuseluting stents have also been shown to be effective in this setting. Recently, Almalla et al performed a retrospective analysis of 174 patients with bare metal in-stent restenosis. Patients were treated with either a paclitaxel-eluting stent $(n=95)$ or an everolimus-eluting stent $(\mathrm{n}=79) \cdot{ }^{74}$ At 1 year, target lesion revascularization was greater for the paclitaxel-eluting stent $(11.5 \%$ versus $1 \% ; P=0.019)$, without significant differences in rates of myocardial infarction, death, or stent thrombosis.

\section{Small vessels}

Even a small degree of late lumen loss can compromise a vessel when the reference diameter is of limited size. Consequently, the minimal late loss seen with everolimus-eluting stents is well suited for use in smaller arteries. The SPIRIT Small Vessel study evaluated the use of everolimus-eluting stents in vessels $2.25 \mathrm{~mm}$ in diameter. ${ }^{75}$ At 1 year, target lesion revascularization was reported in only $5 \%$ of patients and stent thrombosis in $1.5 \%$. These outcomes compare favorably with other studies of small vessels, and suggest that the limited late loss was not offset by an increase in stent thrombosis.

\section{Newer everolimus-eluting stents}

Everolimus has proven to be a safe and highly effective antiproliferative drug, and new stent engineering is improving its means of delivery and, potentially, its safety profile (Table 4). To this end, the PROMUS Element Plus ${ }^{\mathrm{TM}}$ (Boston Scientific) was launched within the last year, replacing the previous cobalt chromium platform with a platinum chromium alloy. ${ }^{76}$ This upgraded platform improves stent deliverability, 
Table 4 Overview of everolimus-eluting stents available in United States

\begin{tabular}{llll}
\hline & $\begin{array}{l}\text { XIENCE } \\
\mathbf{V}^{\text {TM } *}\end{array}$ & $\begin{array}{l}\text { XIENCE } \\
\text { PRIME }\end{array}$ & $\begin{array}{l}\text { PROMUS } \\
\text { Element Plus }\end{array}$ \\
\hline Composition & $\begin{array}{l}\text { Cobalt- } \\
\text { Chromium }\end{array}$ & $\begin{array}{l}\text { Cobalt- } \\
\text { Chromium }\end{array}$ & $\begin{array}{l}\text { Platinum- } \\
\text { Chromium }\end{array}$ \\
Diameters available & $2.25-4.0 \mathrm{~mm}$ & $\begin{array}{l}2.25-4.0 \mathrm{~mm} \\
2.25-4.0 \mathrm{~mm}\end{array}$ \\
Lengths available & $8-28 \mathrm{~mm}$ & $8-38 \mathrm{~mm}$ & $8-32 \mathrm{~mm}$ \\
Nominal pressure & 8 ATM & 8 ATM & II ATM \\
& $(2.25-2.75)$ & $(2.25-2.75)$ & \\
& 9 ATM & I0 ATM & \\
Maximum & $(3.0-4.0)$ & $(3.0-4.0)$ & \\
postdilation & $3.5 \mathrm{~mm}$ & $3.25 \mathrm{~mm}$ & $2.75 \mathrm{~mm}(2.25)$ \\
Diameter & $(2.25-3.0)$ & $(2.25-2.5)$ & $3.5 \mathrm{~mm}$ \\
& $4.5 \mathrm{~mm}$ & $3.75 \mathrm{~mm}$ & $(2.5-2.75)$ \\
& $(3.5-4.0)$ & $(2.75-3.0)$ & $4.25 \mathrm{~mm}$ \\
& & $4.5 \mathrm{~mm}$ & $(3.0-3.5)$ \\
& & $(3.5-4.0)$ & $5.75 \mathrm{~mm}(4.0)$ \\
\hline
\end{tabular}

Note: *Data abstracted from individual indications for use.

radial strength, and side branch access. Comparative studies with other drug-eluting stents have yet to be published, but in PLATINUM (the Prospective, Randomized, Multicenter Trial to Assess an Everolimus-Eluting Coronary Stent System for the Treatment of up to Two De Novo Coronary Artery Lesions), the new platform was found to be noninferior to the earlier everolimus-eluting stents in both safety and efficacy measures. Everolimus is also the drug of choice in the early clinical studies of bioresorbable stents, where its antiproliferative effects coupled with a temporary platform may be the ideal combination for the next generation of stents. ${ }^{77}$

The currently available versions of the everolimus-eluting stent are summarized in Table 4. The Xience platform (including Xience Prime ${ }^{\mathrm{TM}}$; Abbott Vascular) is available in sizes 2.25-4.0 $\mathrm{mm}$ and lengths up to $38 \mathrm{~mm}$. The PROMUS Element Plus ${ }^{\mathrm{TM}}$ stent is available in sizes of $2.25-4.0 \mathrm{~mm}$ and in lengths up to $32 \mathrm{~mm}$. A $38 \mathrm{~mm}$ option is expected soon and should be available by the time this review is published.

\section{Cost-effectiveness}

Drug-eluting stents reduce the need for target vessel revascularization compared with bare metal stents, and thereby result in superior cost-effectiveness. ${ }^{78,79}$ Even when taking into account the increased cost of long-term dual antiplatelet medications, a single center site reported an incremental 3-year cost-effectiveness ratio per target vessel revascularization avoided ranging from $\$ 4703$ to $\$ 6379 .{ }^{79}$ Comparisons between drug-eluting stents are limited, although no significant difference in cost-effectiveness was reported when comparing the zotarolimus-eluting stent with either paclitaxel-eluting stents or sirolimus-eluting stents in the ENDEAVOR III and IV trials..$^{80,81}$ In an age of market- driven costs, where each new stent iteration exerts downward pressure on earlier stents, one would expect to find continued cost-effectiveness among drug-eluting stents directly related to decreased target vessel revascularization.

\section{Conclusion}

In the 35 years since Gruntzig introduced PTCA, the search for an effective, safe percutaneous solution for obstructive coronary artery disease has evolved. The introduction of everolimus-eluting stents has bridged the long-term efficacy of first-generation sirolimus-eluting stents with a long-term safety profile similar to that of bare metal stents. Despite very low late lumen loss, no significant increase in late stent thrombosis has been identified. Everolimuseluting stents have proven to be a versatile, safe platform with excellent long-term results in a wide range of patients and lesions.

\section{Disclosure}

The authors report no conflicts of interest in this work.

\section{References}

1. Coronary angioplasty versus medical therapy for angina: The second randomised intervention treatment of angina (RITA-2) trial. Rita-2 trial participants. Lancet. 1997;350:461-468.

2. Serruys PW, de Jaegere P, Kiemeneij F, et al. A comparison of balloonexpandable-stent implantation with balloon angioplasty in patients with coronary artery disease. Benestent study group. N Engl J Med. 1994;331: 489-495.

3. Mauri L, Hsieh WH, Massaro JM, Ho KK, D’Agostino R, Cutlip DE. Stent thrombosis in randomized clinical trials of drug-eluting stents. N Engl J Med. 2007;356:1020-1029.

4. Leon MB, Nikolsky E, Cutlip DE, et al. Improved late clinical safety with zotarolimus-eluting stents compared with paclitaxel-eluting stents in patients with de novo coronary lesions: 3-year follow-up from the ENDEAVOR IV (randomized comparison of zotarolimus- and paclitaxel-eluting stents in patients with coronary artery disease) trial. JACC Cardiovasc Interv. 2010;3:1043-1050.

5. Stone GW, Midei M, Newman W, et al. Randomized comparison of everolimus-eluting and paclitaxel-eluting stents: Two-year clinical follow-up from the clinical evaluation of the Xience $\mathrm{V}$ everolimus eluting coronary stent system in the treatment of patients with de novo native coronary artery lesions (SPIRIT) iii trial. Circulation. 2009;119: 680-686.

6. Boden WE, O'Rourke RA, Teo KK, et al. Optimal medical therapy with or without PCI for stable coronary disease. $N$ Engl J Med. 2007;356: 1503-1516.

7. Agostoni P, Biondi-Zoccai GG, Gasparini GL, et al. Is bare-metal stenting superior to balloon angioplasty for small vessel coronary artery disease? Evidence from a meta-analysis of randomized trials. Eur Heart J. $2005 ; 26: 881-889$

8. Fischman DL, Leon MB, Baim DS, et al. A randomized comparison of coronary-stent placement and balloon angioplasty in the treatment of coronary artery disease. Stent Restenosis Study Investigators. N Engl J Med. 1994;331:496-501.

9. Buller CE, Dzavik V, Carere RG, et al. Primary stenting versus balloon angioplasty in occluded coronary arteries: The Total Occlusion Study of Canada (TOSCA). Circulation. 1999;100:236-242. 
10. Cutlip DE, Chauhan MS, Baim DS, et al. Clinical restenosis after coronary stenting: Perspectives from multicenter clinical trials. $J \mathrm{Am}$ Coll Cardiol. 2002;40:2082-2089.

11. Nayak AK, Kawamura A, Nesto RW, et al. Myocardial infarction as a presentation of clinical in-stent restenosis. Circ J. 2006;70:1026-1029.

12. Morice MC, Serruys PW, Sousa JE, et al. A randomized comparison of a sirolimus-eluting stent with a standard stent for coronary revascularization. $N$ Engl J Med. 2002;346:1773-1780.

13. Moses JW, Leon MB, Popma JJ, et al. Sirolimus-eluting stents versus standard stents in patients with stenosis in a native coronary artery. N Engl J Med. 2003;349:1315-1323.

14. Stone GW, Ellis SG, Cox DA, et al. A polymer-based, paclitaxel-eluting stent in patients with coronary artery disease. N Engl J Med. 2004;350: 221-231

15. Vezina C, Kudelski A, Sehgal SN. Rapamycin (AY-22,989), a new antifungal antibiotic. I. Taxonomy of the producing streptomycete and isolation of the active principle. J Antibiot (Tokyo). 1975;28:721-726.

16. Abdelmalek MF, Humar A, Stickel F, et al. Sirolimus conversion regimen versus continued calcineurin inhibitors in liver allograft recipients: A randomized trial. Am J Transplant. 2012;12:694-705.

17. Chan S. Targeting the mammalian target of rapamycin (mTOR): A new approach to treating cancer. Br J Cancer. 2004;91:1420-1424.

18. Gallo R, Padurean A, Jayaraman T, et al. Inhibition of intimal thickening after balloon angioplasty in porcine coronary arteries by targeting regulators of the cell cycle. Circulation. 1999;99:2164-2170.

19. Sousa JE, Costa MA, Abizaid AC, et al. Sustained suppression of neointimal proliferation by sirolimus-eluting stents: One-year angiographic and intravascular ultrasound follow-up. Circulation. 2001;104: 2007-2011.

20. Sheiban I, Villata G, Bollati M, Sillano D, Lotrionte M, Biondi-Zoccai G. Next-generation drug-eluting stents in coronary artery disease: Focus on everolimus-eluting stent (Xience V). Vasc Health Risk Manag. 2008;4:31-38

21. Morice MC, Serruys PW, Barragan P, et al. Long-term clinical outcomes with sirolimus-eluting coronary stents: Five-year results of the RAVEL trial. J Am Coll Cardiol. 2007;50:1299-1304.

22. Weisz G, Leon MB, Holmes DR Jr, et al. Five-year follow-up after sirolimus-eluting stent implantation results of the SIRIUS (sirolimuseluting stent in de-novo native coronary lesions) trial. J Am Coll Cardiol. 2009;53:1488-1497.

23. Lemos PA, Serruys PW, van Domburg RT, et al. Unrestricted utilization of sirolimus-eluting stents compared with conventional bare stent implantation in the "real world": The rapamycin-eluting stent evaluated at Rotterdam Cardiology Hospital (RESEARCH) registry. Circulation 2004;109:190-195.

24. Spaulding C, Henry P, Teiger E, et al. Sirolimus-eluting versus uncoated stents in acute myocardial infarction. $N$ Engl $\mathrm{J} \mathrm{Med}$. 2006;355:1093-1104.

25. Axel DI, Kunert W, Goggelmann C, et al. Paclitaxel inhibits arterial smooth muscle cell proliferation and migration in vitro and in vivo using local drug delivery. Circulation. 1997;96:636-645.

26. Grube E, Silber S, Hauptmann KE, et al. Taxus I: Six- and twelvemonth results from a randomized, double-blind trial on a slow-release paclitaxel-eluting stent for de novo coronary lesions. Circulation. 2003;107:38-42.

27. Colombo A, Drzewiecki J, Banning A, et al. Randomized study to assess the effectiveness of slow- and moderate-release polymer-based paclitaxel-eluting stents for coronary artery lesions. Circulation. 2003;108:788-794.

28. Stone GW, Lansky AJ, Pocock SJ, et al. Paclitaxel-eluting stents versus bare-metal stents in acute myocardial infarction. $N$ Engl J Med. 2009;360:1946-1959.

29. Morice MC, Colombo A, Meier B, et al. Sirolimus- vs paclitaxel-eluting stents in de novo coronary artery lesions: The REALITY trial: A randomized controlled trial. JAMA. 2006;295:895-904.

30. Windecker S, Remondino A, Eberli FR, et al. Sirolimus-eluting and paclitaxel-eluting stents for coronary revascularization. $N$ Engl J Med. 2005;353:653-662.
31. Raber L, Wohlwend L, Wigger M, et al. Five-year clinical and angiographic outcomes of a randomized comparison of sirolimuseluting and paclitaxel-eluting stents: Results of the sirolimus-eluting versus paclitaxel-eluting stents for coronary revascularization late trial. Circulation. 2011;123:2819-2828.

32. Galloe AM, Thuesen L, Kelbaek H, et al. Comparison of paclitaxel- and sirolimus-eluting stents in everyday clinical practice: The SORT OUT II randomized trial. JAMA. 2008;299:409-416.

33. Williams DO, Abbott JD, Kip KE. Outcomes of 6906 patients undergoing percutaneous coronary intervention in the era of drug-eluting stents: Report of the DESCOVER Registry. Circulation. 2006;114:2154-2162.

34. Simonton CA, Brodie B, Cheek B, et al. Comparative clinical outcomes of paclitaxel- and sirolimus-eluting stents: Results from a large prospective multicenter registry - STENT group. J Am Coll Cardiol. 2007;50:1214-1222.

35. Ong AT, Serruys PW, Aoki J, et al. The unrestricted use of paclitaxelversus sirolimus-eluting stents for coronary artery disease in an unselected population: One-year results of the taxus-stent evaluated at Rotterdam Cardiology Hospital (T-SEARCH) registry. J Am Coll Cardiol. 2005;45:1135-1141.

36. Daemen J, Wenaweser P, Tsuchida K, et al. Early and late coronary stent thrombosis of sirolimus-eluting and paclitaxel-eluting stents in routine clinical practice: Data from a large two-institutional cohort study. Lancet. 2007;369:667-678.

37. Ong AT, McFadden EP, Regar E, de Jaegere PP, van Domburg RT, Serruys PW. Late angiographic stent thrombosis (last) events with drug-eluting stents. J Am Coll Cardiol. 2005;45:2088-2092.

38. Pfisterer M, Brunner-La Rocca HP, Buser PT, et al. Late clinical events after clopidogrel discontinuation may limit the benefit of drug-eluting stents: An observational study of drug-eluting versus bare-metal stents. J Am Coll Cardiol. 2006;48:2584-2591.

39. Guagliumi G, Sirbu V, Musumeci G, et al. Examination of the in vivo mechanisms of late drug-eluting stent thrombosis findings from optical coherence tomography and intravascular ultrasound imaging. JACC Cardiovasc Interv. 2012;5:12-20.

40. Joner M, Finn AV, Farb A, et al. Pathology of drug-eluting stents in humans: delayed healing and late thrombotic risk. J Am Coll Cardiol. 2006;48:193-202.

41. Virmani R, Guagliumi G, Farb A, et al. Localized hypersensitivity and late coronary thrombosis secondary to a sirolimus-eluting stent: Should we be cautious? Circulation. 2004;109:701-705.

42. Joner M, Nakazawa G, Finn AV, et al. Endothelial cell recovery between comparator polymer-based drug-eluting stents. J Am Coll Cardiol. 2008;52:333-342.

43. Hansi C, Arab A, Rzany A, Ahrens I, Bode C, Hehrlein C. Differences of platelet adhesion and thrombus activation on amorphous silicon carbide, magnesium alloy, stainless steel, and cobalt chromium stent surfaces. Catheter Cardiovasc Interv. 2009;73:488-496.

44. Chitkara K, Pujara K. Drug-eluting stents in acute coronary syndrome: is there a risk of stent thrombosis with second-generation stents? Eur J Cardiovasc Med. 2010;1:20-24.

45. Fajadet J, Wijns W, Laarman GJ, et al. Randomized, 1lind, multicenter study of the endeavor zotarolimus-eluting phosphorylcholine-encapsulated stent for treatment of native coronary artery lesions: Clinical and angiographic results of the ENDEAVOR II trial. Circulation. 2006;114:798-806.

46. Leon MB, Mauri L, Popma JJ, et al. A randomized comparison of the endeavor zotarolimus-eluting stent versus the taxus paclitaxel-eluting stent in de novo native coronary lesions 12-month outcomes from the ENDEAVOR IV trial. J Am Coll Cardiol. 2010;55:543-554.

47. Kandzari DE, Leon MB, Popma JJ, et al. Comparison of zotarolimus-eluting and sirolimus-eluting stents in patients with native coronary artery disease: a randomized controlled trial. J Am Coll Cardiol. 2006;48:2440-2447.

48. Rasmussen K, Maeng M, Kaltoft A, et al. Efficacy and safety of zotarolimus-eluting and sirolimus-eluting coronary stents in routine clinical care (SORT OUT III): A randomised controlled superiority trial. Lancet. 2010;375:1090-1099. 
49. Park DW, Kim YH, Yun SC, et al. Comparison of zotarolimus-eluting stents with sirolimus- and paclitaxel-eluting stents for coronary revascularization: The ZEST (comparison of the efficacy and safety of zotarolimus-eluting stent with sirolimus-eluting and paclitaxel-eluting stent for coronary lesions) randomized trial. J Am Coll Cardiol. 2010;56:1187-1195.

50. Grube E, Sonoda S, Ikeno F, et al. Six- and twelve-month results from first human experience using everolimus-eluting stents with bioabsorbable polymer. Circulation. 2004;109:2168-2171.

51. Serruys PW, Ong AT, Piek JJ, et al. A randomized comparison of a durable polymer everolimus-eluting stent with a bare metal coronary stent: The SPIRIT FIRST trial. EuroIntervention. 2005;1:58-65.

52. Serruys PW, Ruygrok P, Neuzner J, et al. A randomised comparison of an everolimus-eluting coronary stent with a paclitaxel-eluting coronary stent: The SPIRIT II trial. Euro Intervention. 2006;2:286-294.

53. Claessen BE, Beijk MA, Legrand V, et al. Two-year clinical, angiographic, and intravascular ultrasound follow-up of the Xience V everolimus-eluting stent in the treatment of patients with de novo native coronary artery lesions: the SPIRIT II trial. Circ Cardiovasc Interv. 2009;2:339-347.

54. Stone GW, Midei M, Newman W, et al. Comparison of an everolimuseluting stent and a paclitaxel-eluting stent in patients with coronary artery disease: a randomized trial. JAMA. 2008;299:1903-1913.

55. Stone GW, Rizvi A, Newman W, et al. Everolimus-eluting versus paclitaxel-eluting stents in coronary artery disease. $N$ Engl J Med. 2010;362:1663-1674.

56. Stone GW, Rizvi A, Sudhir K, et al. Randomized comparison of everolimus- and paclitaxel-eluting stents. 2-year follow-up from the SPIRIT (clinical evaluation of the Xience V everolimus eluting coronary stent system) IV trial. J Am Coll Cardiol. 2011;58:19-25.

57. Kedhi E, Joesoef KS, McFadden E, et al. Second-generation everolimuseluting and paclitaxel-eluting stents in real-life practice (COMPARE): A randomised trial. Lancet. 2010;375:201-209.

58. Smits PC, Kedhi E, Royaards KJ, et al. 2-year follow-up of a randomized controlled trial of everolimus- and paclitaxel-eluting stents for coronary revascularization in daily practice. COMPARE (Comparison Of The Everolimus Eluting Xience-V Stent With The Paclitaxel Eluting Taxus Liberte stent in all-comers: a randomized open label trial). J Am Coll Cardiol. 2011;58:11-18.

59. Onuma Y, Kukreja N, Piazza N, et al. The everolimus-eluting stent in real-world patients: 6-month follow-up of the X-SEARCH (Xience V stent evaluated at Rotterdam Cardiac Hospital) registry. J Am Coll Cardiol. 2009;54:269-276.

60. Park KW, Chae IH, Lim DS, et al. Everolimus-eluting versus sirolimus-eluting stents in patients undergoing percutaneous coronary intervention: The EXCELLENT (Efficacy of Xience/Promus versus Cypher to reduce late loss after stenting) randomized trial. J Am Coll Cardiol. 2011;58:1844-1854.

61. Serruys PW, Silber S, Garg S, et al. Comparison of zotarolimus-eluting and everolimus-eluting coronary stents. $N$ Engl J Med. 2010;363:136-146.

62. Kastrati A, Massberg S, Ndrepepa G. Is diabetes the Achilles' heel of limus-eluting stents? Circulation. 2011;124:869-872.

63. Stettler C, Allemann S, Wandel S, et al. Drug eluting and bare metal stents in people with and without diabetes: Collaborative Network meta-analysis. BMJ. 2008;337:a1331.

64. Kim WJ, Lee SW, Park SW, et al. Randomized comparison of everolimus-eluting stent versus sirolimus-eluting stent implantation for de novo coronary artery disease in patients with diabetes mellitus (ESSENCE-DIABETES): Results from the ESSENCE-DIABETES trial. Circulation. 2011;124:886-892.

65. Stone GW, Kedhi E, Kereiakes DJ, et al. Differential clinical responses to everolimus-eluting and paclitaxel-eluting coronary stents in patients with and without diabetes mellitus. Circulation. 2011;124:893-900.

66. Valenti R, Migliorini A, Signorini U, et al. Impact of complete revascularization with percutaneous coronary intervention on survival in patients with at least one chronic total occlusion. Eur Heart J. 2008;29:2336-2342.
67. Valenti R, Vergara R, Migliorini A, et al. Comparison of everolimus-eluting stent with paclitaxel-eluting stent in long chronic total occlusions. Am J Cardiol. 2011;107:1768-1771.

68. Tamura T, Kimura T, Morimoto T, et al. Three-year outcome of sirolimus-eluting stent implantation in coronary bifurcation lesions: The provisional side branch stenting approach versus the elective twostent approach. Euro Intervention. 2011;7:588-596.

69. Lansky AJ, Yaqub M, Hermiller JB, et al. Side branch occlusion with everolimus-eluting and paclitaxel-eluting stents: Three-year results from the SPIRIT III randomised trial. Euro Intervention. 2010;6 Suppl J: J44-J52.

70. Burzotta F, Trani C, Todaro D, et al. Prospective randomized comparison of sirolimus- or everolimus-eluting stent to treat bifurcated lesions by provisional approach. JACC Cardiovasc Interv. 2011;4:327-335.

71. Herrador JA, Fernandez JC, Guzman M, Aragon V. Comparison of zotarolimus- versus everolimus-eluting stents in the treatment of coronary bifurcation lesions. Catheter Cardiovasc Interv. 2011;78: 1086-1092.

72. Stone GW, Ellis SG, O'Shaughnessy CD, et al. Paclitaxel-eluting stents vs vascular brachytherapy for in-stent restenosis within baremetal stents: The TAXUS V ISR randomized trial. JAMA. 2006;295: 1253-1263.

73. Holmes DR Jr, Teirstein P, Satler L, et al. Sirolimus-eluting stents vs vascular brachytherapy for in-stent restenosis within bare-metal stents: The SISR randomized trial. JAMA. 2006;295:1264-1273.

74. Almalla M, Schroder JW, Pross V, Stegemann E, Marx N, Hoffmann R. Everolimus-eluting versus paclitaxel-eluting stents for treatment of bare metal stent restenosis. Am J Cardiol. 2011;108:518-522.

75. Cannon LA, Simon DI, Kereiakes D, et al. The Xience nano ${ }^{\mathrm{TM}}$ everolimus eluting coronary stent system for the treatment of small coronary arteries: The SPIRIT small vessel trial. Catheter Cardiovasc Interv. November 25, 2011.

76. Stone GW, Teirstein PS, Meredith IT, et al. A prospective, randomized evaluation of a novel everolimus-eluting coronary stent: The PLATINUM (a prospective, randomized, multicenter trial to assess an everolimus-eluting coronary stent system [Promus Element] for the treatment of up to two de novo coronary artery lesions) trial. J Am Coll Cardiol. 2011;57:1700-1708.

77. Serruys PW, Onuma Y, Dudek D, et al. Evaluation of the second generation of a bioresorbable everolimus-eluting vascular scaffold for the treatment of de novo coronary artery stenosis: 12-month clinical and imaging outcomes. J Am Coll Cardiol. 2011;58:1578-1588.

78. Bakhai A, Stone GW, Mahoney E, et al. Cost effectiveness of paclitaxel-eluting stents for patients undergoing percutaneous coronary revascularization: Results from the TAXUS-IV trial. J Am Coll Cardiol. 2006;48:253-261.

79. Schafer PE, Sacrinty MT, Cohen DJ, et al. Cost-effectiveness of drug-eluting stents versus bare metal stents in clinical practice. Circ Cardiovasc Qual Outcomes. 2011;4:408-415.

80. Eisenstein EL, Leon MB, Kandzari DE, et al. Long-term clinical and economic analysis of the Endeavor zotarolimus-eluting stent versus the Cypher sirolimus-eluting stent: 3-year results from the ENDEAVOR III trial (randomized controlled trial of the Medtronic Endeavor drug [ABT-578] eluting coronary stent system versus the Cypher sirolimuseluting coronary stent system in de novo native coronary artery lesions). JACC Cardiovasc Interv. 2009;2:1199-1207.

81. Leon MB, Kandzari DE, Eisenstein EL, et al. Late safety, efficacy, and cost-effectiveness of a zotarolimus-eluting stent compared with a paclitaxel-eluting stent in patients with de novo coronary lesions: 2-year follow-up from the ENDEAVOR IV trial (randomized, controlled trial of the Medtronic Endeavor drug [ABT-578] eluting coronary stent system versus the Taxus paclitaxel-eluting coronary stent system in de novo native coronary artery lesions). JACC Cardiovasc Interv. 2009;2:1208-1218. 
Vascular Health and Risk Management

Dovepress

\section{Publish your work in this journal}

Vascular Health and Risk Management is an international, peerreviewed journal of therapeutics and risk management, focusing on concise rapid reporting of clinical studies on the processes involved in the maintenance of vascular health; the monitoring, prevention and treatment of vascular disease and its sequelae; and the involvement of metabolic disorders, particularly diabetes. This journal is indexed on PubMed Central and MedLine. The manuscript management system is completely online and includes a very quick and fair peer-review system, which is all easy to use. Visit http://www.dovepress.com/ testimonials.php to read real quotes from published authors.

Submit your manuscript here: http://www.dovepress.com/vascular-health-and-risk-management-journal 